Gut, 1985, 26, 843-847

Liver and biliary

\title{
Endoscopic variceal pressure measurements: response to isosorbide dinitrate
}

\author{
J DAWSON, P GERTSCH, F MOSIMANN, R WEST, AND E ELIAS
}

From the Department of Medicine, Queen Elizabeth Hospital, Birmingham and Service de Chirurgie B, Centre Hospitalier Universitaire Vaudois, Lausanne, Switzerland

SUMMARY An endoscopic pressure sensor has been evaluated in the measurement of oesophageal variceal pressure and its response to drug ingestion. The variceal pressure showed a highly significant correlation with the splenic pulp pressure $(r=0.97)$ in six patients with liver disease of diverse aetiology and with hepatic venous wedge pressure $(r=0.92)$ in eight alcoholic cirrhotic men. Intraduodenal infusion of isosorbide dinitrate in the cirrhotics produced no change in wedge pressure or endoscopic variceal pressure despite profound falls in arterial systolic pressure. Thus isosorbide dinitrate appears to be of no value in treating portal hypertension. This study establishes the endoscopic pressure sensor as a valuable tool in screening drugs in this condition.

Expectation that long term drug therapy may reduce the incidence of rebleeding from oesophageal varices has been raised by the reported success of propranolol. ${ }^{12}$ Propranolol is, however, a potentially toxic drug in liver disease ${ }^{3-5}$ and therapy in patients with varices may be hazardous. ${ }^{6}$ Alternative drugs must first be shown to reduce portal pressure before embarking on clinical evaluation. Existing methods of measuring portal pressure (splenic puncture, mesenteric vein cannulation and hepatic venous catheterisation with wedging) are invasive and unsuitable for drug screening. In this study we have used a newly described pneumatic pressure sensor ${ }^{7}$ fitted to a standard endoscope to assess the response of portal pressure to intraduodenal isosorbide dinitrate, which on theoretical grounds appeared the most promising of a number of drugs postulated to reduce portal pressure when given orally.

\section{Methods}

\section{ENDOSCOPIC PRÉSSURE MEASUREMENTS}

The pressure sensor was attached to the tip of a standard Olympus GIFQ or Machida FGI-SD endoscope (Fig. 1) and connected by a double lumen catheter passed through the biopsy channel to a controlling module consisting of electronic mano-

Address for correspondence: Dr J Dawson, Department of Medicine, Clatterbridge Hospital, Wirral, Merseyside.

Received for publication 8 October 1984 meter and minicompressor. The sensor, a prototype developed in Lausanne, works on the simple principle that pressure within a varix is equal to pressure necessary to compress the varix. ${ }^{7}$ Air is passed from the controlling module, through one channel of the catheter to the head of the pressure sensor where it passes through a central aperture and under a latex membrane to a peripheral channel from which air returns through the second channel of the catheter to the controlling module (Fig. 2). When the pressure head is applied to a varix the flow of air is occluded and the pressure in the closed circuit automatically rises until it just overcomes the obstruction to airflow. At this point the pressure in the circuit is equal to the pressure within the varix. This pressure is then measured electronically and produced as a signal which is recorded on a suitable pen recorder (Fig. 3). The pressure trace shows variations with respiration and smaller perturbations

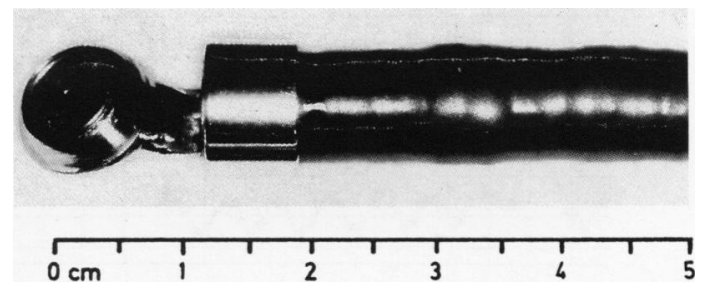

Fig. 1 Pressure sensor attached to tip of endoscope. 
Fig. 2 Schematic representation of the pressure sensor, double lumen catheter and controlling module.

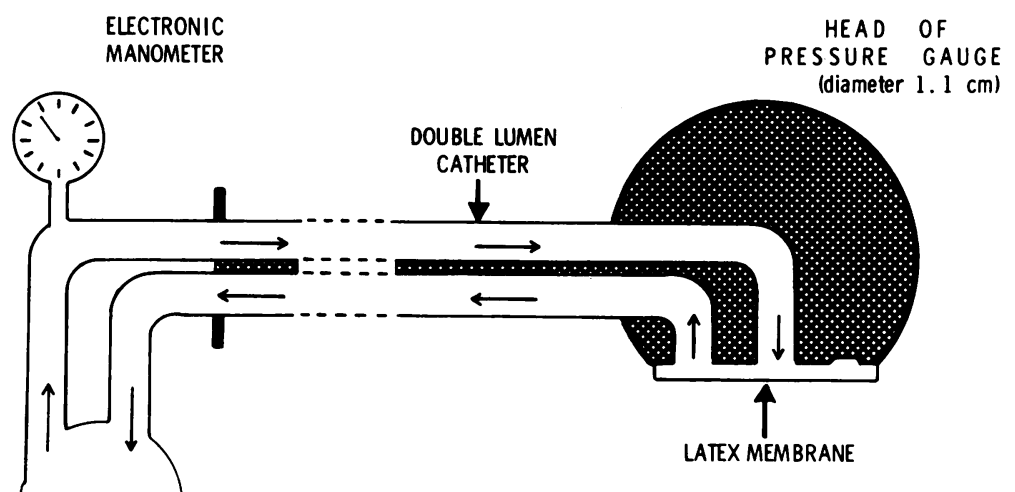

AIR PUMP due to transmitted heartbeat. The variceal pressure is taken as the mean of these variations. The characteristic variceal trace is recognised immediately on application of the gauge to a varix and as a function of intravariceal pressure does not depend on the pressure of application. Air is initially insufflated to visualise the varices before application but after application to a varix no further air insufflation is necessary. During oesophageal peristalsis the sensor may be dislodged from the varix but a trace is reobtained usually without major repositioning. The pressure gauge is calibrated before and after each endoscopy using a water column. The calibration was not observed to change during the endoscopies. The endoscopic variceal pressure does not significantly change during a single endoscopy, nor between endoscopies carried out on the same patient under similar conditions when measured a few days apart. All measurements in the current study were done by a single endoscopist.

VALIDATION OF PRESSURE MEASUREMENTS

The variceal pressure was recorded in six patients with diverse aetiology of liver disease (Table) and compared at a later date with the previously recorded splenic pulp pressure recorded at splenoportography in these patients.

\section{DRUG STUDY}

Eight male patients with alcoholic cirrhosis who had recently bled from large (grade 3 or 4$)^{8}$ oesophageal varices but were otherwise healthy were studied. After initial sedation with $10 \mathrm{mg}$ diazepam a simultaneous record was taken of the hepatic venous wedge pressure using the occlusive balloon technique ${ }^{9}$ and endoscopic variceal pressure and continuous arterial systolic pressure monitoring initiated. Isosorbide dinitrate, $5 \mathrm{mg}$, was the infused via a fine bore tube placed in the duodenum. Readings of wedge, variceal, and arterial systolic pressure were taken over a 30 minute period after drug infusion. The wedge and variceal pressure were simultaneously documented on a 2 channel pen recorder and the arterial pressure documented manually from a digital recorder at 30 second intervals.

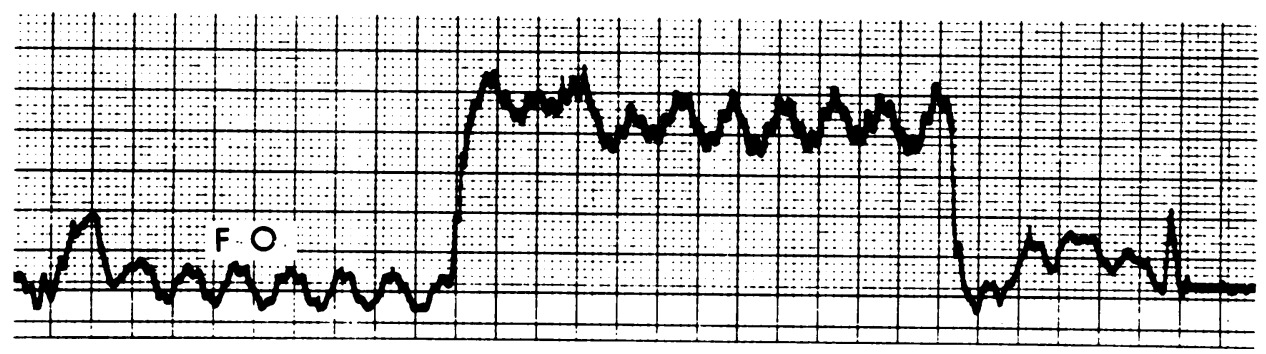

Fig. 3 Pressure trace showing pressure recorded with pressure sensor free in oesophageal lumen (FO) and subsequently after application to a varix. 
Table Details of patients in endoscopic variceal pressure validation study

\begin{tabular}{llllll}
\hline $\begin{array}{l}\text { Patient/Aetiology } \\
\text { Extrahepatic }\end{array}$ & Age & Sex & $\begin{array}{l}\text { Previous } \\
\text { variceal bleed }\end{array}$ & $\begin{array}{l}\text { Splenic pulp } \\
\text { pressure }\left(\mathrm{cm} \mathrm{H}_{2} \mathrm{O}\right)\end{array}$ & $\begin{array}{l}\text { Endoscopic variceal } \\
\text { pressure }\left(\mathrm{cm} \mathrm{H}_{2} \mathrm{O}\right)\end{array}$ \\
$\begin{array}{l}\text { portal hypertension } \\
\text { (aetiology unknown) }\end{array}$ & 54 & $\mathrm{M}$ & Yes & 39 & 38 \\
$\begin{array}{l}\text { Extrahepatic } \\
\text { portal hypertension } \\
\text { (post-pancreatitis) }\end{array}$ & 35 & $\mathrm{M}$ & No & & \\
$\begin{array}{l}\text { Extrahepatic } \\
\text { portal hypertension } \\
\text { (post pancreatitis) }\end{array}$ & 56 & $\mathrm{M}$ & Yes & $18 \cdot 5$ & $17 \cdot 5$ \\
$\begin{array}{l}\text { Alcoholic cirrhosis } \\
\begin{array}{l}\text { Cryptogenic cirrhosis } \\
\text { Primary biliary cirrhosis }\end{array}\end{array}$ & 63 & $\mathrm{M}$ & Yes & 41 & 40 \\
\hline
\end{tabular}

\section{Results}

\section{VALIDATION}

A highly significant correlation between endoscopic variceal pressure and splenic pulp pressure $(r=0.97$, Fig. 4) was noted in the six patients studied. There was also a significant correlation between basal hepatic venous wedge pressure and endoscopic variceal pressure in the eight alcoholic patients in the second part of the study ( $\mathrm{r}=0.92$, Fig. 5 ).

DRUG STUDY

The pressure readings before and after isosorbide dinitrate infusion are shown in Fig. 6. There was no change in either endoscopic variceal (mean change: plus $1 \cdot 2 \pm 0 \cdot 3 \mathrm{~cm} \mathrm{H}_{2} \mathrm{O}$ ) or hepatic venous wedge

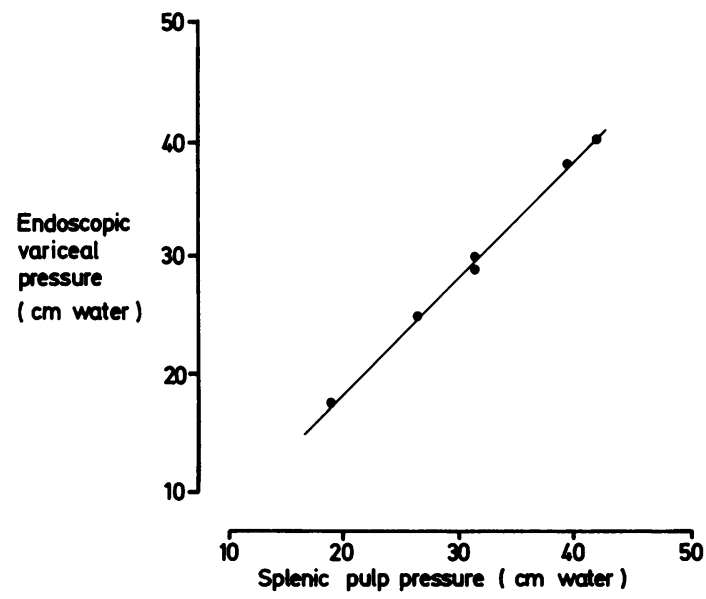

Fig. 4 Correlation of endoscopic variceal pressure with splenic pulp pressure in patients with varices of diverse aetiology (Table). pressure (mean change: $-0 \cdot 9 \pm 0 \cdot 4 \mathrm{~cm} \mathrm{H}_{2} \mathrm{O}$ ). In six of the eight patients, however, a profound fall in arterial systolic pressure (mean change $42 \pm 11$ $\mathrm{mmHg}$ ) was noted.

\section{Discussion}

These studies indicate that the endoscopic pressure sensor is a useful and effective instrument for measuring portal pressure. The variceal pressure recorded correlates well with conventional estimates of portal pressure. Unlike previously described methods the sensor is non-invasive and therefore has many potential applications. In this study its value in drug screening has been shown.

Many alternatives to propranolol for lowering

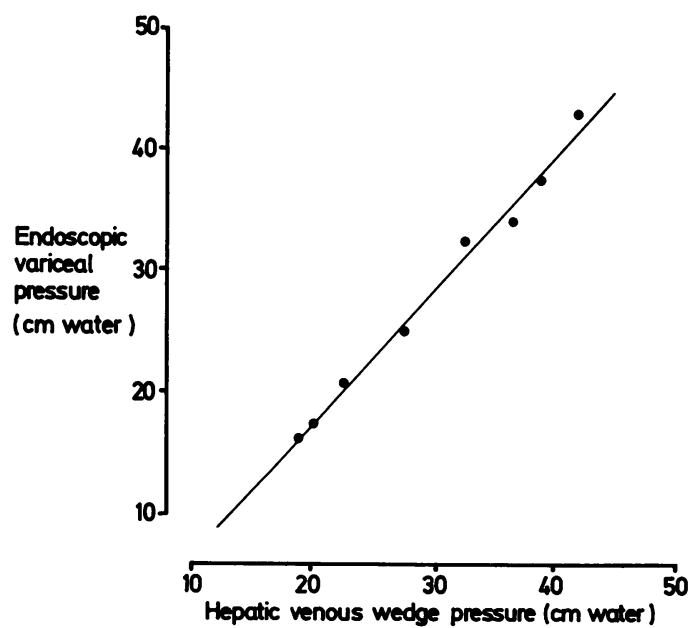

Fig. 5 Correlation of endoscopic variceal pressure with simultaneously measured hepatic venous wedge pressure in patients with alcoholic cirrhosis. 


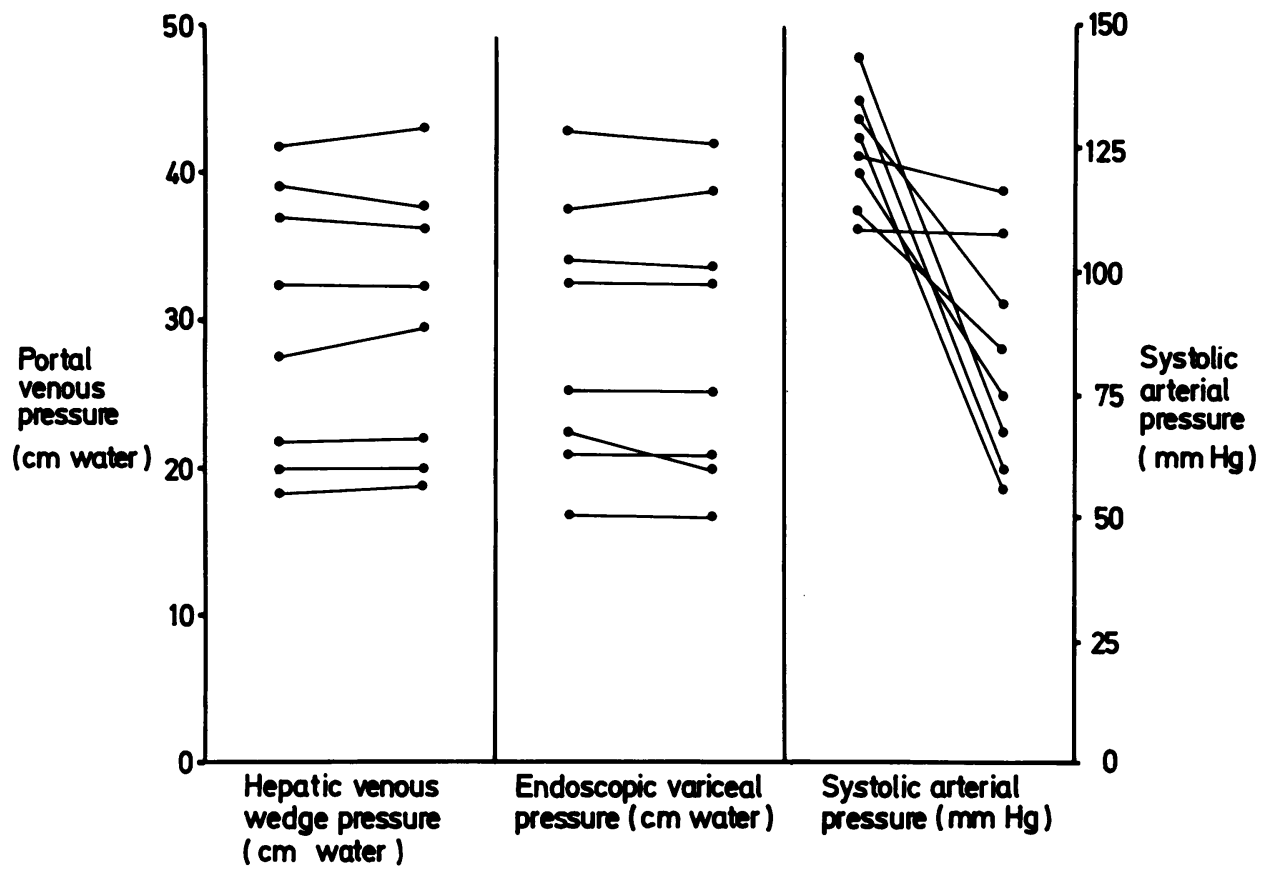

Fig. 6 Hepatic venous wedge pressure, endoscopic variceal pressure and systolic arterial pressure before and after intraduodenal instillation of isosorbide dinitrate.

portal pressure have been suggested. Most of these including vasopressin, glypressin, and somatostatin, are unsuitable for long term use because they require parenteral infusion and have unacceptable toxicity. There is some evidence, however, that the short acting nitrate, glyceryl trinitrate, given orally may be beneficial and non-toxic. ${ }^{10} 1 \mathrm{P}$ The long acting nitrates more suitable for long term prophylaxis have not previously been evaluated in man although isosorbide dinitrate has been shown to reduce portal pressure in cats. ${ }^{12}$ In our study isosorbide dinitrate was shown not only to be without effect on portal pressure but potentially hazardous because of its systemic hypotensive effect in these cirrhotic patients. This surprising effect may be because of the increased amounts of the drug, which has a high first pass hepatic extraction, ${ }^{2}$ reaching the systemic circulation in patients with impaired hepatic function. The maintenance of portal pressure during arterial hypotension is presumably analogous to the maintenance of systemic venous pressure during hypotension, although the latter was not measured in this study. Nevertheless the study has established the possibility of rapidly and simply screening drugs of possible value in treating portal hypertension using the endoscopic pressure sensor.
This paper is based on the Hopkins Endoscopy Prize winning Presentation, British Society of Gastroenterology, April 1984.

The authors wish to acknowledge the help and advice given by Professor $\mathrm{R}$ Mosimann and Dr R Cockel. We thank Mrs Dawn Campbell for typing the manuscript. The study was financed in part by Imperial Chemical Industries PLC and the Queen Elizabeth Hospital, Birmingham Endowment Fund.

\section{References}

1 Lebrec D, Nouel O, Corbic M, Benhamou J-P. Propranolol - A medical treatment for portal hypertension. Lancet 1980; 2: 180-2.

2 Lebrec D, Poynard T, Hilliard P, Benhamou J-P. Propranolol for prevention of recurrent gastrointestinal bleeding in patients with cirrhosis: a controlled study. $N$ Engl J Med 1981; 305: 1371-4.

3 Conn HO. Propranolol in the treatment of portal hypertension: a caution. Hepatology 1982; 2: 641-4.

4 Van Buuren H, Van Der Velden PC, Koorevar G, Silberbusch J. Propranolol increases arterial ammonia in liver cirrhosis. Lancet 1982; 2: 951-2. 
5 Tarver D, Walt D, Dunk A, Jenkins W, Sherlock S. Precipitation of hepatic encephalopathy by propranolol in cirrhosis. $\mathrm{Br}$ Med J 1983; 287: 585.

6 Burroughs AK, Jenkins WJ, Sherlock S, et al. Controlled trial of propranolol for the prevention of recurrent variceal haemorrhage in patients with cirrhosis. $N$ Engl J Med 1983; 309: 1539-42.

7 Mosimann R. Mesure de la pression des varices oesophagiennes par voie endoscopique non sanglante. Helv Chir Acta 1980; 48: 261-4.

8 Paquet K, Prophylactic endoscopic sclerosing treatment of the oesophageal wall in varices. A prospective controlled randomised trial. Endoscopy 1982; 14: 4-5.

9 Groszmann R, Glickman M, Blei A, Storer E, Conn H. Wedged and free hepatic venous pressure measured with a balloon catheter. Gastroenterology 1978; 76: 253-8.
10 Gibson P, McLean A, Jakobovits A, Dudley F. Medical management of portal hypertension: hypothesis and preliminary investigations [Abstract] Gut 1982; 23: A446.

11 Groszmann R, Kravetz D, Bosch J, Glickman M, et al. Nitroglycerin improves the haemodynamic response to vasopressin in portal hypertension. Hepatology 1982; 2: $757-62$.

12 Greenway C. Effects of sodium nitroprusside, isosorbide dinitrate, isoprotorenol, phentolamine and prazosin on hepatic venous responses to sympathetic nerve stimulation in the cat. J Pharmacol Exp Ther 1979; 209: 56-61.

13 Taylor T, Chasseaud LF, and Doyle E. Pharmacokinetics of isosorbide dinitrate after intravenous infusion in human subjects. Biopharm Drug Disp 1980; 1: 149-56. 